This is a pre-publication version of the article accepted for publication: Kelan, E. K., \& Wratil, P. (forthcoming) 'CEOs as Agents of Change and Continuity', Equality, Diversity and Inclusion: An International Journal. DOI 10.1108/EDI-06-2020-0171

\title{
CEOs as Agents of Change and Continuity
}

\section{Abstract}

\section{Purpose}

CEOs are increasingly seen as change agents for gender equality, which means that CEOs have to lead others to achieve gender equality. Much of this leadership is going to happen through talk, which raises the question as to how CEOs talk about gender equality to act as change agents.

\section{Design/methodology/approach}

Drawing on interviews with global CEOs, who have publicly supported gender equality work, the article draws on discourse analysis to understand the arguments CEOs deploy.

\section{Findings}

The analysis shows that CEOs deploy three arguments. First, CEOs argue that women bring special skills to the workplace, which contributes to a female advantage. Second, CEOs argue that the best person for the job is hired. Third, CEOs talk about how biases and privilege permeate the workplace. The analysis shows that CEOs are often invested in essentialised views of gender while holding onto ideals of meritocracy.

\section{Originality}

The article suggests that how leaders talk about gender equality leads to continuity rather than change in regard to gender equality.

Keywords: Change Agents, Chief Executive Officers, Discourse Analysis, Gender, Senior Leaders 


\section{Introduction}

While research on gender and leadership has focused on women's approaches and experiences of leadership, the role of leaders in advancing gender equality has more recently emerged as an important question for gender and leadership (Humbert et al., 2019; Kelan, 2019; Kelan and Wratil, 2018; de Vries, 2015). This conceptual shift from looking at women in leadership to looking at how leaders can create gender equality is significant because it allows consideration of the practices of leaders both women and men - in respect to gender equality. CEOs in particular recognise gender equality as one of their top priorities (McKinsey, 2012). Often, being an advocate for gender equality is expressed by naming those individuals 'champions'. The language of champions might make such behaviours more appealing to others who want to adopt it, but it also resonates with the idea that leaders engaging in gender equality are heroic (Kelan and Wratil, 2018; de Vries, 2015). Prior research has looked at how men in leadership positions hold more essential views, which hinders their potential to be change agents (Humbert et al., 2019). Other research has highlighted how men as change agents for gender equality are positioned, which in turn limits how men in leadership can unfold their power to change gender relations (Kelan, 2019). While it has been established how senior leaders can act as change agents (Kelan and Wratil, 2018), it has so far not been explored how senior leaders talk about gender equality. This is particularly important because they will lead others through their talk.

The aim of this article is therefore to understand which 'winning arguments' CEOs deploy when they discuss gender equality. In discourse analytic research, winning arguments are units of sense making that are commonly deployed to make a convincing argument when talking about an issue; they are also called interpretative repertoires (Wetherell and Potter, 1988). The article is organised as follows. The article first reviews the literature on leaders as change agents for gender equality before explaining the methodology. The analysis highlights which arguments for gender equality CEOs use. The discussion sets the findings in the context of the literature and the conclusion offers a summary and suggests further research. The article contributes towards understanding how CEOs' essentialist conceptions of gender, together with a strong belief in merit, are not facilitating change in regard to gender equality but rather contribute to its continuity. 


\section{Leading Toward Equality - CEOs as Change Agents}

There is a large body of research that has explored women as leaders. A detailed review of this body of work is beyond the scope of this article but it should be noted that much of the debates on women and leadership have focused on gender differences (cf. Liff and Wajcman, 1996). Research has explored topics such as women's and men's leadership styles (Eagly and Johannesen-Schmidt, 2001; Eagly and Johnson, 1990), women's experiences in leadership (Elliott and Stead, 2008; Stead, 2013), the linguistic resources women leaders use (Baxter, 2010), or how women can develop their leadership skills through special programmes, mentoring, and coaching (Ely et al., 2011; Hopkins et al., 2008; Noe, 1988). It has also been shown that the association between men, masculinity, management and leadership is challenging for women leaders because they do not fit the mould of the ideal leader (Koenig et al., 2011; Schein, 1973; Sczesny et al., 2004). Women in leadership are change agents in as much as that they challenge the masculine subtext of leadership. It is thus not surprising that research on gender and leadership regularly locates the ability of organisational transformation in women who are implicitly expected to be change agents.

There are two central ideas that are commonly mobilised in talking about women and leadership: essentialism and merit. In regard to essentialism, the idea that women and men have different essences that they bring to leadership, has been central in much writing on the topic (for a critical discussion, see Billing and Alvesson, 2000). Contemporary gender theories see gender essentialism as problematic and instead suggest that gender is a social construction; gender is then often seen as an activity or 'doing' (Butler, 1990; West and Zimmerman, 1987). Presumed essences that are believed to be associated with men or women attempt to fix gender rather than see gender as something that is achieved. It is then not surprising that gender difference thinking is regularly deemed essentialist because it presumes that all women inherently, naturally and universally have those skills that are different from men's skills (for reviews, see Ahl, 2004; Barrett \& Phillips, 1992; Lorber, 1993; Moore, 1994). Gender essentialism then refers to the fact that individuals presume that there is a fixed essence that distinguishes men and women (Brescoll et al., 2013). Gender essentialism often recurs to biology, suggesting that biology leads men and women to 
show different skills and abilities (Fausto-Sterling, 2000; Lorber, 1993). Essentialism is also problematic because it informs gender difference thinking that often positions women as implicitly inferior in organisational life, which then means that women need to be trained to be in leadership positions (Ely and Meyerson, 2000). Furthermore, gender essentialism can be the basis for gender discrimination (Humbert et al., 2019).

The female advantage discourse is an example of potentially essentialist thinking. The female advantage perspective argues that women bring special skills to the workplace that are valuable and important (Helgesen, 1990). This in turn often leads to the assertion that the future belongs to women (Rosener, 1990; Rosin, 2012). Academic research has regularly questioned the female or feminine advantage perspective (Ainsworth, 2002; Billing and Alvesson, 2000; Eagly and Carli, 2003; Fletcher, 1994; Simpson et al., 2010; Webb, 1997). When critically discussing this 'special contribution' perspective, Alvesson and Billing (2009) state that such thinking is based on the idea that women have unique experiences and talents, which lead to different values, and ways of thinking, behaving and acting. As women's contribution is constructed as complementary to that of men, women can help organisations to be more effective. This perspective is commonly seen as gender essentialist as it presumes specific gendered essences, which often reflect and reify stereotypes (Billing and Alvesson, 2000; Wajcman, 1996). Such an essentialist view is used to argue for more women in the workplace and is regularly linked to the business case for gender equality: by having more women with essentialised skills, business is able to do better. The special contribution that women are said to bring might relate for instance to their social skills, which are regularly seen as something typically feminine, while at the same time, not being rewarded as such (Fletcher, 1999; Kelan, 2008). Such female advantage discourses have been critiqued because they make it rhetorically difficult to argue that gender inequalities continue to exist (Gill et al., 2017).

Merit is another concept that regularly influences the conception of gender, work and leadership (Krefting, 2003; Sliwa and Johansson, 2013). The belief that everyone has a fair chance of succeeding and if one does not succeed, this is largely due to personal inadequacies supports the idea that merit is central (Simpson et al., 2010). This can be 
illustrated in relation to affirmative action. If affirmative action means favouring groups who have been historically disadvantaged, opponents of affirmative action see it as violating merit by giving individuals an unfair advantage (Reyna et al., 2005). This debate is particularly prominent in relation to quotas and targets in the workplace. Following the quota for women on boards in Norway (Seierstad and Opsahl, 2011; Teigen, 2012; Wang and Kelan, 2013), this topic has been widely discussed in the popular media and in businesses. Quotas are often rejected based on the argument that it would allow women to reach positions they are not qualified for, thus lowering merit (cf. Pesonen et al., 2009). Any attempt to rebalance representations is seen as leading to less qualified individuals holding a position. Instead, it is often suggested that women develop their merit by developing their human capital, motivation or confidence (cf. Cech and Blair-Loy, 2010; Gill and Orgad, 2017); it is presumed that this will allow women to advance due to their own merit. However, such a perspective ignores that what is defined as merit might be skewed towards those who are already in position (Ashcraft, 2013; Tienari et al., 2002).

While a lot of research attention has been paid to women leaders, looking at how leaders can create gender inclusion represents a more recent addition to the literature. While middle managers are often reluctant owners of change in regard to gender equality (Lansu et al., 2020), senior leaders are regularly seen as central for changing organisational cultures (Schein, 2010). Leaders can act as role models that others emulate (Sawyer and Valerio, 2018). How leaders talk about gender equality can potentially inspire others to also act on gender equality. Leaders can also put pressure on middle managers to change their practices (Lansu et al., 2020). Prior research has therefore suggested that senior leaders in particular can be powerful agents for change to achieve gender equality (Mattis, 2001; Morrison, 1992; Prime and Moss-Racusin, 2009; Wahl, 2014). The question of how leaders in organisations can act as change agents for gender equality is thus a relevant and important one.

As senior leadership continues to be dominated by men, many of the senior leaders who are supporting gender equality can be expected to be men (Sawyer and Valerio, 2018). Men and women can be change agents for gender equality but face different dynamics: men are often perceived as more effective because men are seen as not 
personally benefiting from gender equality; women as change agents are perceived as self-serving when they lobby for gender equality (de Vries, 2015). Similarly, it has been shown that women are judged less competent when they are engaged in gender equality, whereas men appear as more competent (Hekman et al., 2017). However, de Vries (2015) also points out that in calling for men in senior leadership positions to become agents of change, the gender order is reified. It is men who through their positional power can be constructed as being able to help women by achieving gender equality, which feeds into perception that women need men's help. This also resonates with the idea that men in senior leadership can act as 'champions', which appeals to a sense of heroism (Kelan and Wratil, 2018).

The research discussed below builds on prior research in the field. Past research showed how men in leadership are more likely to hold essentialist views of gender than men in non-leadership roles or women in leadership or non-leadership (Humbert et al., 2019). This research has drawn on a large-scale EU-wide survey to look at how gender essentialist conceptions are related to various gender equality interventions and has shown that leadership positions were also less likely to support gender quotas. These gender beliefs cast some doubt over the ability that men in leadership positions can act as change agents for gender equality (Humbert et al., 2019). While the survey was able to document gender beliefs, the research did not provide any indication of how men are invited to join the conversation on gender equality in organisations.

Our research is also informed by research, which looked specifically at how men as change agents for gender equality are invited to join the conversation. This research has shown that men are invited to construct their identities as gender equality partners based on three subject positions: a man can be an inclusive leader who knows about the impact of biases on decision making and mitigates this; the smart strategist recognises that business can be improved through focusing on women as customers and talent; the forced altruist realises that men have to contribute to gender equality as part of the greater good (Kelan, 2019). However the same research also highlights that these subject positions implicitly construct men as disadvantaged and other subject positions such as those that make men's privilege visible are rendered unavailable. Other research has shown how senior leaders support gender equality in their 
organisation as macro change agents: they create accountability in the chain of command, build ownership with their direct reports, talk about gender equality in public fora, lead by example, and initiate and lead culture change (Kelan and Wratil, 2018).

The discussion of prior research has therefore indicated what might hinder men in leadership to engage in gender equality, which subject positions are offered and how senior leaders support gender equality. However there is currently no research that shows how senior leaders talk about gender equality and which conceptions of gender equality they use to convince others that that gender equality is important. Knowing how senior leaders talk about gender equality is important to understand how leaders try to convince others to take action on gender equality. The article thus aims to showcase how senior leaders talk about gender equality to encourage others to take action, which is an area currently not addressed by research.

While much discussion on gender and leadership focuses on women leaders as agents of change, leaders, who have a role model function in organisations, are well-placed to be change agents of gender equality. There is an emerging understanding of how senior leaders can be change agents for gender equality but it is so far unexplored of which arguments of gender equality senior leaders use. The aim of the article is thus to show which 'winning arguments' CEOs deploy when they are talking about gender equality.

\section{Researching Winning Arguments for Gender Equality}

Discourse analytic techniques (Potter and Wetherell, 1987; Wetherell and Potter, 1988) are well suited to show which 'winning arguments' CEOs use in regard to gender equality. Discourse analysis in this version seeks to identify commonly used expressions through which meaning is created. Those constructions are termed interpretative repertoires (Wetherell and Potter, 1988) and are common units of sense making that are regularly deployed to make an argument or explain a specific construction of the world (Gill et al., 2017). Interpretative repertoires are also described as 'winning arguments', which are accepted as part of common sense used to win an argument, which makes them particularly useful for this study. Some research in discourse analysis focuses on emic understandings and a detailed study of 
language details (Speer and Potter, 2000), while other research focuses more on etic understandings and wider ideology (Edley and Wetherell, 1999, 2001). This research follows more the latter interpretation of discourse analysis.

In order to explore how CEOs conceptualise gender, we decided to interview CEOs who have declared their support for gender equality. It can be expected that such a group of CEOs can draw on arguments relating to the importance of gender equality that they would use internally in their organisation, as well as externally with the wider public. As the first author of the article has a wide network of professional contacts, she was able to identify five CEOs who are supportive of gender equality. Others were recruited from a group of CEOs who have signed a statement of support for the Women's Empowerment Principles (WEPs), an initiative by UN Women and the UN Global Compact. Fifteen of the CEOs have signed the WEPs, which means that they are not only likely to support gender equality in their organisation and beyond, but that they might also use similar interpretative repertoires in doing so. Five CEOs had not signed the WEPs but were known to be supporters of gender equality to the first author. Even though the seven principles of the WEPs provide a framework for gender equality, they nevertheless allow organisations and their CEOs a lot of freedom of interpretation, meaning that it can be expected that the comments from the CEOs are distinct and relate also to their industry as well as their global location. The CEOs represented a range of industries as well as global locations. Four companies were in telecommunications, four were professional service firms, three in information communication technologies, two in finance, two in the pharmaceutical industry, and one organisation each in energy, research, insurance, and retail. The final organisation was a conglomerate. Eight organisations were in the European Economic Area, four in North America, four in Asia, three in BRICS (Brazil, Russia, India, China, South Africa) countries and one in the Middle East. The majority of organisations were multinational companies and four were small and medium-sized businesses. Like with most senior positions in organisations, most CEOs are men. Fifteen CEOs identified as men and five as women. The research findings are treated as confidential to protect the identities of the individuals and organisations, and each interviewee was given a pseudonym (Lahman et al., 2015). 
CEOs are time poor and it was therefore decided to keep interviews brief to ensure that CEOs would agree to participate. The first author who conducted the interviews therefore asked for 30 minutes in the CEOs' diaries. The interviews started with running the CEOs through the research aims and gaining consent to participate. The main part of the interview was on average 32 minutes long, with the longest being 50 minutes and the shortest 19 minutes. This excludes the introduction and consent gained at the beginning of the interview and the closing, which normally took around five to ten minutes. Most of the CEOs were excellent communicators and were able to talk not only eloquently but also efficiently, meaning that even fairly short interviews provided rich data.

Due to the global nature of the sample, the interviews were conducted over the phone and recorded using a conference call facility to ensure good audio quality. With telephone interviews, many visual cues are missing and it is therefore more difficult to establish a rapport, and to know when the interviewee has finished a statement. As they were supporters of gender equality in their organisation, most of them were eager to elaborate on their point of view and it was not too difficult to get them talking. While the first author anticipated very polished and partly-rehearsed statements that CEOs had learned from their diversity and inclusion professionals, it was somewhat surprising to see that many CEOs talked freely about the topic. It should be noted that the interviews were conducted in English, which was not the first language of many of the CEOs. This meant that some of them might not have had the finesse of a native speaker, which together with the fact that the interviews were conducted over the phone, resulted in slightly 'choppier' quotes. It was decided not to edit the quotes for better readability to give them an authentic feel. Many of the interviewees not being native speakers in combination with the fact that interviews were conducted over the phone impacted how the author carried out the discourse analysis. As stated before, the emphasis of the project was the etic understanding in relation to wider ideologies, rather than a narrow focus on pauses and figures of speech, as in the emic understanding. A pause in a phone interview might for instance not mean that interviewees are unsure of what to say but instead, it might represent a short connection slip or pause, as one waits for a speaker to finish what they are saying. 
The first author had a detailed interview guide, which included a warm-up question where the CEOs talked about their background, why they are supporting gender equality and what their priorities are, what obstacles there are to achieve gender equality, their understanding of gender equality, factors that influenced that they are supportive of gender equality, what practices they use to support gender equality, and if they had any additions. The material was transcribed verbatim by a professional transcription service and proofread by the first author using a simplified version of the Jefferson system ${ }^{\mathrm{i}}$. The material was then coded using the web application Dedoose by the second author. The first coding was focused more on content, which included codes such as obstacles to gender parity, reasons for supporting gender parity, and women's presumed skills. The second round of coding largely conducted by the first author focused on the interpretative repertoires or winning arguments that were deployed and what discursive effect they had. It involved a reading and re-reading of text extracts until a discursive pattern emerged. This is in line with coding practices common for discourse analysis, where an iterative process between the material and its discursive meaning is central (Potter and Wetherell, 1987). The coding was inclusive, meaning that different segments appeared in different codes. It should also be noted that as is common in discourse analysis (Potter and Wetherell, 1987), the interviewees did not fall neatly into one interpretative repertoire or another. Many in fact drew on multiple interpretative repertoires. As such, it is uncommon in discourse analysis to provide a quantitative breakdown of how many interviewees used one interpretative repertoire over another. However, if only relatively few CEOs drew on certain interpretative repertoires, that is mentioned. This allows the reader to get a better idea of the patterning of the discourse and how frequent certain interpretative repertoires are. We also looked specifically if women and men CEOs used different winning arguments. It could be expected that this is the case because women might for instance reflect on situations where they experienced gender discrimination. However, we could not identify a pattern in that women CEOs used different winning arguments to men CEOs. One reason for this is that we did not ask about personal experiences of gender inequality but focused on the change agency of leaders. Since we had a globally diverse sample, we also paid attention to regional and cultural variations but could not detect any specific patterns. The same is true for industry backgrounds. When analysing the talk, we noticed three distinct yet overlapping, 
interpretative repertoires or winning arguments that were used by the CEOs. Those three interpretative repertoires form the basis of the analysis section.

\section{Winning Arguments for Gender Equality}

In the interviews, the CEOs mobilised three interpretative repertoires to support gender equality. The first argument centered on women's special skills and reflects beliefs around gender essentialism. The second argument focuses on getting the best person for the job. A third interpretative repertoire concerned how bias has to be acknowledged.

\section{The Female Advantage}

The first interpretative repertoire that CEOs used focused on the female advantage, which is based on women's special skills. Those special skills are presented as particularly useful and beneficial in the workplace.

Mortimer: I, I think there are some elements of, er, generalisation that can be (.) true. Um, if I say for example, I think women at very senior level, and, and ((coughs)) in all levels ((coughs)), but senior women in boardrooms (.) remain more emotionally authentic in my experience than their male counterparts. And I think that can be very powerful. Um, so I do think there are some elements of the development of, of, um, er, leaders, er, you know, gender can be a factor inwithout making all women or all men leaders the same, I think there are some attributes that are particularly, er, attributable to one gender or other, that, that should be recognised and positively exploited. Not abused, but positively ex= exploited.

While 'exploiting' might be regarded as something negative, Mortimer makes sure that he stresses that there are some gendered attributes that can be 'positively exploited' in organisations. Mortimer appears aware of the fact that this statement could be seen as a sweeping generalisation. He qualified his account that not all men and women are alike by using a typical disclaimer structure (Hewitt and Stokes, 1975). He nevertheless makes the point that gendered attributes such as being 
authentic in the boardroom is something that can be used by organisations as an advantage.

Similarly, Ingo states the following:

Ingo: And that's from my perspective and it may sound a little clichéd, but it's my experience, all the women leaders that I've been working with are much more in touch with their emotions than my male colleagues. [...] Um, and I think this is very much important because they're also much (.) usually much more courageous when it comes to speak up. So I have, you know, the other day we had a meeting, one of my male colleagues said something, and just looking at the faces of the other male colleagues, I could see that most disagreed but nobody said anything because it happened to be the CFO. And three ladies in the management team all stood up and said, 'no way', you know. And I have seen this, this is not just one instance, I've seen it time and time again.

By saying that it might 'sound a little clichéd', Ingo appears aware that he is making assumptions about all women and that he is not supposed to be doing that. However, he nevertheless proceeds to offer a gender essentialist statement. He talks about women being in touch with their emotions, which presumed gender essentialised skills, but he appears to try to justify it with the fact that women in a meeting spoke up when everyone else was in agreement. He thereby used the well-recognised connecting between women and emotions, which has been analysed in relation to essentialised skills (Kelan, 2008). However, he seems to link that to women speaking up in meetings, which is normally not a core part of the women and emotional skills repertoire. What Ingo appears to be doing is to stretch the well-known repertoire of women and emotions to meetings where this connection appears as beneficial. The consequence is that women appear to add something unique to business.

Adam: We think at [company name], that, you know, the status and role of women is not only, you know, a key to a country's growth potential, but also is a key to a COMPANY'S growth potential and that where women are better represented in management, where women are better represented on the board, where women have a seat at a table, that the decision making process is better; 
erm, the organisation is stronger and its performance will ultimately, er, be better and that's true for non-profits and for profits as well.

Adam suggests that by widening the talent pool, decision making is improved through having a variety of opinions presented. This in turn improves performance. While he does not talk about women as bringing special skills to the table specifically, women's presence seems to account for better decision making.

Talking about gender differences was indeed popular among the CEOs, as Kenneth's account illustrates:

Kenneth: Well, it's a positive attribute because, you know, a lot of um, (.) of how men approach business is all about (.) er, it's, er, what I would call gung ho, it's big talk, it's loud and everything else. Sometimes women don't necessarily come across that way, but they get the job done.

Kenneth stresses that it is a positive attribute that women do not involve themselves in 'big talk' like men but 'get the job done'. Men in this account do not appear as particularly productive but this discursive sacrifice is made to let women and their special skills appear as positive.

Neena: I think there could be different attributes, I think, you know, um, you know, er, communication styles, um, you know, er, different attributes such as, er, sort of level of detail or attention to detail, one might say generally, er, you know, the women are better at it. Well, not, er, not exclusively, but, you know, in many cases, er, some of that is true. So what we find is that just having this rounding out of, um, of, er, of, you know, of the mix in our teams, I think does make us more effective. So it's different styles, different perspectives, (.) and different strengths.

Neena seems aware that her account of gender differences in attributes could be seen as reinforcing stereotypes, which is why she is careful to stress that it is a generalisation. Neena is aware of the danger of stereotyping and therefore disclaims that those skills are not exclusive to women. She nevertheless argues that the special 
skills women bring are central to create the right mix at work. It is this right mix that makes her organisation more effective.

In their attempt to find positive reasons to include women in the workplace, the CEOs often drew on essentialised gender skills and attributes. Most CEOs appear to be aware that these are generalisations, assumptions and stereotypes, but they nevertheless proceed to use them as facts to argue that they help to make organisations more effective. Here, gender essentialism is used to argue for women to be in the workplace because women enhance organisational effectiveness.

\section{The Best Person for the Job}

One of the most frequently used interpretative repertoires entailed that the best person for the job is recruited instead of promoting 'quota women'. The CEOs selected for this research were supporting gender equality and this was regularly equated with increasing the percentage of women in leadership positions in their organisations. However, what was surprising is that most CEOs were extremely careful to argue that having more women in leadership positions does not mean lowering the bar for women and thus compromising merit.

Percy states:

Percy: It's not that, you know, she would get the job, (.) you know, the best person will get the job.

Even though Percy wants to have more women in senior roles, this does not mean that women automatically get the job. Instead, he makes it clear that the best person will get the job, denying that any affirmative action could be used. However, he does not reflect on how definitions of who could the best person are imbued with gender.

Similarly, Ingo states:

Ingo: I have to be honest, I cannot afford to put mediocre people, male or female, in any position, it would kill me.

What Ingo points out here is that not having the best people in his company will lead to his organisation losing competitiveness. The expression 'it would kill me' might 
also relate to his own position and that he would not be able to be the CEO if his company does not perform. His statement must be read in the context of affirmative action, where it is often presumed that increasing the number of women means that the quality of candidates suffers. However, Ingo cannot afford mediocre people of either gender if his business is to be successful.

Craig questions a blind support for gender equality:

Craig: It's not because 'it's female, it's fantastic' - no. There are also female leaders who fail. [...] if you are an evangelist, if you are (.) er:m (.) let's say, totally consumed by the issue, you will only see the positive and not the negative. [...] And also, sometimes, if something doesn't work, you have to be able - and willing - er, to be tough if necessary and not say, 'oh yeah, because this is a female person, I'm not going to do that'. You must make sure that $[\ldots]$ merit comes first.

Craig discursively denies that everything that women do is automatically great. Such 'evangelist' attitudes where only the positive is noted but the negative is ignored do not work in his view. Craig talks about that women leaders can fail and that he would not hesitate to be tough in regard to poor performance, even if it is a woman leader. He justifies this by saying that merit is more important than increasing the number of women in leadership roles.

When asked about gender equality in his organisation, Fabio reads this question as about gender advancement:

Fabio: Yeah, I mean, I think (.) it is= it is still based, you know, in terms of career advancement if that's what we're talking about? You know, there is still, erm, you know, I would hope and believe that there is still in [company name] a, you know, still a sense of meritocracy. So, you know, have we thought about, erm, (.) if you like, erm, (.) specifically favouring women in relation to the advancement of their careers - yes we have thought about it [...] erm, but we don't think it's something HEHE that necessarily is going to serve us that well. [...] Well, I mean, I think the arguments around (.) you know, if 
you do quota-ise then people will just wonder HEHE whether they're only there because of the quota - I think that will very quickly happen.

For Fabio, gender equality in his organisation relates to career advancement of women. He makes clear that in his organisation, achievement is based on merit, and that means that a quota for women to support their career advancement would be counterproductive. However, rather than just arguing that this is detrimental to the organisation in that it undermines the perception of meritocracy, he suggests that it is undermining the competence of women. In other words, being a quota is bad for women. It is notable that Fabio frames his point in the language of quotas.

Similarly, Ingo states:

Ingo: I have to be honest, I was never for quotas, I- you know, like affirmative action and things like this, I- but I think (.) you, you probably need to get the ball rolling.

What Ingo here suggests is that quotas are useful to 'get the ball rolling', but he makes it clear that he does not support affirmative action or quotas.

Similarly, Craig explains why he dislikes quotas:

Craig: Quota is = quota is forced from the outside. I want make a force from the inside. Your ow:n credibility, put it at stake. That's much better than a quota. The quota is, you know, it's not my invention, it's come from the law, I have to pay taxes, I have to do this, my passion is not behind it, my heart is not behind it.

Craig is here arguing that a quota is something forced on organisations from the outside rather than something that the organisation wants to achieve. He seems to suggest that organisations need to have a passion for gender equality to make change happen rather than just being forced to do so.

Adam also orients himself towards quotas:

Adam: If you have a search, whether it's as Vice President of Marketing or Chief Financial Officer or, er, Director of, er, you know, Information 
Technology and you're going to go out there and look for people, just tell your search firm that's working with you on that search, make sure that there are women (.) that you bring to me to be interviewed for that job. And - and - and and if you do that, erm, you'll end up, just by nature of the way you've conducted your search, your numbers will move and - more companies just have to take that simple first step; and I'm not saying they'll automatically get to $50 \%$ like we do- did, but I can tell you this, [Interviewer name], we did it without quotas. Like I said, we simply hired the best person from our finalist pool, which simply had women in them and it was as simple as that.

Rather than using quotas, Adam describes how he instructs search consultants to suggest a gender-balanced slate of candidates. The discursive move to have affirmative search rather than affirmative action means that that the best person of the job is hired instead of fulfilling a quota. While women are considered through affirmative search, they are not 'quota women' who are hired to fulfill a quota rather than their suitability for the position.

To summarise thus far, most CEOs strongly argued against affirmative action or a quota, which they saw as a potential vehicle for less qualified women to get hired or promoted. It is interesting that this interpretative repertoire is a negative one; something that CEOs dislike. They want to have more women but they do not want to have more women through quotas. The argument is then that the best person for the job is hired instead of promoting 'quota women'. Gender equality is only desirable if it is aligned with the business case of having the best person for the job in position.

\section{Making Biases Visible}

While the first two interpretative repertoires were the most regularly deployed, another perspective was mobilised, albeit less frequently. This interpretative repertoire covered biases.

This perspective was often based on the language of bias, as Edgar illustrates:

Edgar: But if I had to give a message to anyone, it's just - treat people based on merit! [...] both the culture and the gender thing (.) are biases. They're ingrained, inherent biases. And, to get people to see that $=$ that this is what 
they are, that they're historical biases, and if you want the best people and the most diverse people sitting around you making sure the organisation is successful, you have to acknowledge those biases and move beyond them.

Edgar frames his argument in the context of merit and links it to having the best people. While this sounds very much like the best person for the job argument, Edgar adds an important twist to his argument. He seems to suggest that biases influence who is seen as the best person. For Edgar, acknowledging biases is central to ensure that who is the best person for the job is not obscured by biases.

While Edgar alludes to the fact that bias is hindering the selection of the best person for the job, it is Adam who makes gender equality relevant for men.

Adam: So I think, fundamentally (.) you know, ma:les and in some parts of the world, white males or wealthy white males or wealthy males are unfairly advantaged. Erm, and, you know, we do not have a meritocracy when we, erm, oppress one or more groups we have, erm, you know, a system run by the people who are benefitted by [sic] that oppression so, I mean, er, (.) I think that, you know, fundamentally men have to understand that they are being unfairly advantaged by this. That what we're doing is, we are allowing a sort of - we are allowing a certain mediocrity to persist because instead of advancing THE best people, regardless of race, creed, colour or gender, we're advancing certain people and not allowing others to fully participate - in the contest and so - I think we have to change, erm, male thinking too.

Adam was the only CEO who spelled out the privilege that white, wealthy men enjoy. It is a poignant statement because Adam could be counted as one of those white, wealthy men. For Adam, it is therefore central to make men aware of their privilege to create gender equality. He suggests that currently, men are unaware of their privilege, and without such an awareness, not the best person for the job is selected. What Adam, like Edgar, offers is a questioning of the common winning argument that the best people for the job should be hired. Instead, Edgar argues that not the best people are hired because of biases, and Adam suggests that men are unfairly advantaged in a system that favours men. This means that men profit from an invisible affirmative action that is hidden from sight. 
While only Adam talked about men's privilege, other CEOs referred to mechanisms through which men's privilege is maintained.

Neena: And of course then, at the end of the day, from [company name] perspective, the job goes to the best person. But I think, (.) you know, it's all about making sure that people are not overlooked. Because there are certain pockets where it's all about the old boy [sic] network, you know, and guys areguys think of other guys when there is a role. I think we need to make sure that there is a systematic way by which we, we inject into any consideration who are the best three people and among the best three people, certainly there must be a woman who's equipped to do this job.

While part of Neena's account draws on the best person for the job logic, she is aware that it is men's old boys networks that often contribute to the fact that women are overlooked and therefore, not the best person for the job is recruited.

Similarly, Quincy also talks about how the traditional business model favoured men: Quincy: And, um, and, and when I say the old model is, if you look at the way business was done in France, er, including when I was younger, it was very much an old boy, er, school model. So you developed business relationship through, um, old boy clubs, er, through male events like certain kind of sport and through networking for men only. And with, er, the belief that you had to sacrifice your, er, family life to be successful in business, so the belief was that men were out doing business while the women were attending the family. Er, that was actually a model that was only existing for a small part of the 20th century, it was not existing before that part of the 20th century, so it was not like a forever model. Um, and we believe that (.) globalisation, change of generation and also basically the model was completely wrong (...) And we tried to break the mould thing, (.) of course we cannot ignore, er, the French old, er, social, er, dogma, but it's going to change, and we are going also to change it. So we didn't promote (.) er, people to partnership based on, er, duplication of the old model saying, well, you have to be partner, you have to that part- part of that network, part of that club, which were only men club at the time. Er, to become partner you need to have potential, er, and to show your potential and to 
try to make something new. And obviously that opens the (.) talent pool to a whole new set of talents.

Quincy describes what he saw as the traditional but now outdated model of doing business, which favoured men through schools, networks and sports, as well as sacrificing family life. He thereby spells out some of the privilege that men enjoyed. He also stresses that this model is on the way out and that it is not the way forward. While he does not talk about men's privilege, it serves as an illustration for how business favoured men.

While only one interviewee talked explicitly about making men's privilege visible, it is clear that other CEOs understood the dynamics that helped men to support their powerful positions and how bias played a role in that. This interpretative repertoire casts a very different light on gender equality because it necessitates men to realise that they have been in positions of power and that processes of finding the best person for the job are biased. This winning argument was nascent and much less frequently drawn on.

\section{Discussion}

The winning arguments that CEOs use to support gender equality are important because they are instrumental in convincing others of gender equality. The analysis has shown that the CEOs draw on three interpretative repertoires when they talk about gender equality. First, CEOs talk about the female advantage through the special skills women bring to the workplace. Second, CEOs argue that the best person for the job should get it rather than a token or 'quota woman'. The final and less common argument is based on how bias and privilege are relevant in assessing merit.

It was notable that the first two winning arguments use common sense assumptions for gender equality: that women have unique skills and that affirmative action-like practices hinder the best person to get to the job would by many people be accepted without critically questioning it. As such, the CEOs draw on popularly accepted notions of women in the workplace and gender equality. With non-essentialism being an important part of discussions on gender (Alvesson and Billing, 2002; Billing and Alvesson, 2000; Fletcher, 1999; Kelan, 2008), it can be noted that the social 
construction of gender and the dangers of essentialism have not reached CEOs who deploy essentialist perspectives on gender. Women's special skills were used as a positive argument for having more women in the workplace. This discursive move is reminiscent of benevolent sexism (Glick and Fiske, 1996), where one uses seemingly positive gender evaluations. However, these are ultimately reifying gender relations and power inequities in the workplace. It also resonates with arguments that the female advantage is used to deny the existence of gender inequality (Gill et al., 2017). While one could argue that CEOs have simply not been exposed to such academic theories, it is notable that the language constructions used in many of the extracts indicate that the CEOs are aware of their sweeping generalisations about women's skills. CEOs draw on women's essential difference in a well-meaning way to argue for more women in the workplace. However, they nevertheless draw on a reductionist understanding of gender that risks reifying gender difference by presuming essentialised skills. Even though those essentialised skills are presented as beneficial, such constructions nevertheless use an understanding of gender that limits women and indeed men.

While CEOs were supportive of gender equality, they held onto the idea that the best person for the job is a gender-neutral construction. Academic research has not only engaged with affirmative action and quotas (Pesonen et al., 2009; Reyna et al., 2005) but also problematised the notions of gender neutrality in organisations (Billing and Alvesson, 2000; Fletcher, 1999; Wajcman, 1996). However, there was limited understanding of the fact that how current organisations run is gendered and as such, simply arguing for the best person for the job will not create gender equality. Who the best person for a job is follows, after all, a logic of the ideal worker (Acker, 1990); as academic research on gendered organisations has shown that men often find it easier to fall into the ideal worker template and that is the case, even when women are constructed as supposedly ideal workers (Kelan, 2008). However, it is notable that some CEOs recognised this dynamic when they talked about making biases and men's advantages visible. This echoes the academic literature on masculinities, which has argued that men's privilege needs to be made explicit for gender equality to emerge (Collinson and Hearn, 2005; Connell, 1995; Connell and Wood, 2005; Flood and Pease, 2005). It also aligns with academic research that has argued that biases not only have to be made visible but that decision-making practices have to be adapted to 
avoid that bias can take hold (Bohnet et al., 2016). Bar a few exceptions, CEOs did not talk about men's privilege and how organisational structures and systems might be gendered. This could be due to the fact that CEOs have profited from those gendered systems and structures because many of them belong to the group of privileged men. However, particularly CEOs who are in privileged positions might be able to question existing systems and structures and offer more radical thinking, which includes reflecting on men's privilege.

It is not surprising that most CEOs hold onto merit because questioning merit would mean to question how businesses are currently run. Furthermore, CEOs will have risen through the ranks and will presume that their success is based on merit. Questioning the existing system of merit is radical. Those who do use the language of bias and privilege in those discussions, which suggests that they have engaged with diversity and inclusion practitioners who often use these terms. Overall, the discursive construction ensures that women feel welcomed but it also does not threaten the status quo. Acknowledging that organisational decision making is biased and that the current system might prefer men would be challenging the power dynamics in organisations. In sum, CEOs are using a discursive construction that is designed to encourage women but that does not threaten the status quo. Only a few CEOs advocate for a more profound change through suggesting that how merit is assessed needs to change.

\section{Conclusion}

With leaders increasingly asked to lead on gender equality, this article contributed an understanding to the literature which winning arguments for gender equality CEOs use to achieve this. The article has shown that CEOs firstly draw on essentialised conceptions of women's special skills entailed in the female advantage argument. Second, CEOs hold onto ideas of merit by stressing the best-person-for-the-job logic. This counteracts ideas of quotas, which are constructed as unmeritocratic. Only a few accounts of CEOs draw on how biases and privileges are hindering gender equality. By drawing on the female advantage argument, CEOs appear to empower women. CEOs also ensure that they are not questioning the status quo. While CEOs can be important change agents for gender equality, they could do that by leaving commonplace assumptions around gender essentialism and merit behind and instead 
focus on changing gendered systems and structures. Acknowledging and changing gendered systems and structures might therefore for a useful way to talk about gender equality for CEOs. The article has therefore shown how a narrow understanding of gender is limiting CEOs to transform gender relations.

While the CEOs in this study have signalled their support for gender equality publicly, further research could explore how CEOs who have not spoken publicly about gender equality see change towards gender equality. It could also be explored in how far CEOs leave a legacy in regard to changing systems and structures in relation to gender or if those changes do not outlive a CEO's tenure. It would also be insightful to explore how other organisational members understand the arguments CEOs deploy and how they are communicated in the organisation and thus bringing in followers' perspectives. For instance, how are middle managers reacting to those messages (Lansu et al., 2020). This would help to gain a better understanding if a CEO who is supportive of gender equality has an effect on how the organisation is changing towards more gender equality. Another area of further research could relate to regional and cultural differences, as well as industry differences. While our research could not detect any differences in terms of global location or industry, further in-depth research might uncover such differences in how CEOs speak about gender equality. While CEOs attempt to create change in regard to gender equality, they inadvertently often foster its continuity.

\section{References}

Acker, J. (1990), “Hierarchies, Jobs, Bodies: A Theory of Gendered Organizations”, Gender \& Society, Vol. 4 No. 2, pp. 139-158.

Ahl, H. (2004), The Scientific Reproduction of Gender Inequality: A Discourse Analysis of Research Texts on Women's Entrepreneurship, Copenhagen Business School Press, Copenhagen.

Ainsworth, S. (2002), “The 'Feminine Advantage': A Discursive Analysis of the Invisibility of Older Women Workers", Gender, Work and Organization, Vol. 9 No. 5, pp. 579-601.

Alvesson, M. and Billing, Y.D. (2002), "Beyond Body-Counting - a discussion of the social construction of gender at work", in Aaltio, I. and Mills, A.J. (Eds.), 
Gender, Identity and the Culture of Organizations, Routledge, London, pp. 7291.

Alvesson, M. and Billing, Y.D. (2009), Understanding Gender and Organizations, Sage, London.

Ashcraft, K.L. (2013), “The glass slipper: 'Incorporating' occupational identity in management studies", Academy of Management Review, Vol. 38 No. 1, pp. 631.

Barrett, M. and Phillips, A. (1992), "Introduction”, in Barrett, M. and Phillips, A. (Eds.), Destabilizing Theory - Contemporary Feminist Debates, Polity, Cambridge, pp. 1-9.

Baxter, J. (2010), The Language of Female Leadership, Palgrave, Basingstoke.

Billing, Y.D. and Alvesson, M. (2000), "Questioning the Notion of Feminine Leadership: A Critical Perspective on Gender Labelling of Leadership", Gender, Work and Organization, Vol. 7 No. 3, pp. 144-154.

Bohnet, I., van Geen, A. and Bazerman, M. (2016), "When Performance Trumps Gender Bias: Joint vs. Separate Evaluation”, Management Science, Vol. 62 No. 5, pp. 1225-1234.

Brescoll, V.L., Uhlmann, E.L. and Newman, G.E. (2013), “The effects of systemjustifying motives on endorsement of essentialist explanations for gender differences", Journal of Personality and Social Psychology, Vol. 105 No. 6, pp. 891-908.

Butler, J. (1990), Gender Trouble: Feminism and the Subversion of Identity, Routledge, London.

Cech, E.A. and Blair-Loy, M. (2010), "Perceiving Glass Ceilings? Meritocratic versus Structural Explanations of Gender Inequality among Women in Science and Technology”, Social Problems, Vol. 57 No. 3, pp. 371-397.

Collinson, D.L. and Hearn, J. (2005), "Men and Masculinities in Work, Organizations, and Management", in Kimmel, M.S., Hearn, J. and Connell, R.W. (Eds.), Handbook of Studies on Men \& Masculinities, Sage, London, pp. 289310.

Connell, R.W. (1995), Masculinities, Polity, Cambridge.

Connell, R.W. and Wood, J. (2005), "Globalization and Business Masculinities”, Men and Masculinities, Vol. 7 No. 4, pp. 347-364.

Eagly, A.H. and Carli, L.L. (2003), “The female leadership advantage: An evaluation 
of the evidence", The Leadership Quarterly, Vol. 14 No. 6, pp. 807-834.

Eagly, A.H. and Johannesen-Schmidt, M.C. (2001), "The Leadership Styles of Women and Men”, Journal of Social Issues, Vol. 57 No. 4, pp. 781-798. Eagly, A.H. and Johnson, B.T. (1990), “Gender and Leadership Style: A MetaAnalysis”, Psychological Bulletin, Vol. 108 No. 2, pp. 233-256.

Edley, N. and Wetherell, M. (1999), “Imagined futures: Young men's talk about fatherhood and domestic life", British Journal of Social Psychology, Vol. 38, pp. $181-194$

Edley, N. and Wetherell, M. (2001), “Jekyll and Hyde: Men’s Construction of Feminism and Feminists", Feminism \& Psychology, Vol. 11 No. 4, pp. 439-457. Elliott, C. and Stead, V. (2008), “Learning from Leading Women's Experience: Towards a Sociological Understanding”, Leadership, Vol. 4 No. 2, pp. 159-180. Ely, R., Ibarra, H. and Kolb, D.M. (2011), “Taking Gender Into Account: Theory and Design for Women's Leadership Development Programs", Academy of Management Learning and Education, Vol. 10 No. 3, pp. 474-493.

Ely, R. and Meyerson, D. (2000), “Advancing Gender Equity in Organizations: The Challenge and Importance of Maintaining a Gender Narrative”, Organization, Vol. 7 No. 4, pp. 589-608.

Fausto-Sterling, A. (2000), Sexing the Body: Gender Politics and the Construction of Sexuality, Basic Books, New York.

Fletcher, J.K. (1994), "Castrating the Female Advantage: Feminist Standpoint Research and Management Science", Journal of Management Inquiry, Vol. 3 No. 1, pp. $74-82$.

Fletcher, J.K. (1999), Disappearing Acts: Gender, Power, and Relational Practice, MIT Press, Cambridge (MA).

Flood, M. and Pease, B. (2005), “Undoing Men's Privilege and Advancing Gender Equality in Public Sector Institutions", Policy and Society, Vol. 24 No. 4, pp. $119-138$.

Gill, R., Kelan, E.K. and Scharff, C.M. (2017), “A Postfeminist Sensibility at Work”, Gender, Work \& Organization, Vol. 24 No. 3, pp. 226-244.

Gill, R. and Orgad, S. (2017), "Confidence culture and the remaking of feminism”, New Formations, Vol. 91 No. 91, pp. 16-34.

Glick, P. and Fiske, S.T. (1996), "The Ambivalent Sexisms Inventory: Differentiatig hostile and benevolent sexism", Journal of Personality and Social Psychology, 
Vol. 70 No. 3, pp. 491-513.

Hekman, D.R., Johnson, S.K., Foo, M.-D. and Yang, W. (2017), "Does DiversityValuing Behavior Result in Diminished Performance Ratings for Non-White and Female Leaders?”, Academy of Management Journal, Vol. 60 No. 2, pp. 771797.

Helgesen, S. (1990), The Female Advantage: Women's Ways of Leadership, Doubleday Currency, New York.

Hewitt, J.P. and Stokes, R. (1975), “Disclaimers”, American Sociological Review, Vol. 40 No. 1, pp. 1-11.

Hopkins, M.M., O’Neil, D.A., Passarelli, A. and Bilimoria, D. (2008), “Women’s leadership development strategic practices for women and organizations", Consulting Psychology Journal: Practice and Research, Vol. 60 No. 4, pp. 348365.

Humbert, A.L., Kelan, E.K. and van den Brink, M. (2019), “The Perils of Gender Beliefs for Men Leaders as Change Agents for Gender Equality”, European Management Review, p. forthcoming.

Kelan, E.K. (2008), "Emotions in a Rational Profession: The Gendering of Skills in ICT work", Gender, Work \& Organization, Vol. 15 No. 1, pp. 49-71.

Kelan, E.K. (2019), “The Inclusive Leader, The Smart Strategist and The Forced Altruist: Subject Positions for Men as Gender Equality Partner”, European Management Review.

Kelan, E.K. and Wratil, P. (2018), "Post-heroic Leadership, Tempered Radicalism and Senior Leaders as Change Agents for Gender Equality", European Management Review, Vol. 15 No. 1, pp. 5-18.

Koenig, A.M., Eagly, A.H., Mitchell, A. a and Ristikari, T. (2011), “Are leader stereotypes masculine? A meta-analysis of three research paradigms.", Psychological Bulletin, Vol. 137 No. 4, pp. 616-642.

Krefting, L.A. (2003), "Intertwined Discourses of Merit and Gender: Evidence from Academic Employment in the USA", Gender, Work \& Organization, Vol. 10 No. 2, pp. 260-278.

Lahman, M.K.E., Rodriguez, K.L., Moses, L., Griffin, K.M., Mendoza, B.M. and Yacoub, W. (2015), “A Rose By Any Other Name Is Still a Rose?

Problematizing Pseudonyms in Research", Qualitative Inquiry, Vol. 21 No. 5, pp. $445-453$. 
Lansu, M., Bleijenbergh, I. and Benschop, Y. (2020), “Just talking? Middle managers negotiating problem ownership in gender equality interventions", Scandinavian Journal of Management, Pergamon, Vol. 36 No. 2, p. 101110.

Liff, S. and Wajcman, J. (1996), “'Sameness' and 'Difference' Revisited: Which Way Forward For Equal Opportunity Initiatives?”, Journal of Management Studies, Wiley/Blackwell (10.1111), Vol. 33 No. 1, pp. 79-94.

Lorber, J. (1993), "Believing is Seeing: Biology as Ideology”, Gender and Society, Vol. 7 No. 4, pp. 568-581.

Mattis, M.C. (2001), “Advancing women in business organizations: Key leadership roles and behaviors of senior leaders and middle managers", Journal of Management Development, Vol. 20 No. 4, pp. 371-388.

McKinsey. (2012), “Women Matter 2012: Making the Breakthrough”, McKinsey, available at: http://www.mckinsey.com/client_service/organization/latest_thinking/women_m atter.

Moore, H. (1994), "The Divisions within Sex, Gender and Sexual Difference", in Moore, H. (Ed.), A Passion for Difference, Polity Press, Cambridge, pp. 9-27. Morrison, A.M. (1992), The New Leaders - Guidelines on Leadership Diversity in America, Jossey-Bass, San Francisco.

Noe, R.A. (1988), "Women and Mentoring: A Review and Research Agenda", Academy of Management Review, Academy of Management Briarcliff Manor, NY 10510 , Vol. 13 No. 1, pp. 65-78.

Pesonen, S., Tienari, J. and Vanhala, S. (2009), “The boardroom gender paradox", Gender in Management: An International Journal, Emerald Group Publishing Limited, Vol. 24 No. 5, pp. 327-345.

Potter, J. and Wetherell, M. (1987), Discourse and Social Psychology: Beyond Attitudes and Behaviour, Sage, London.

Prime, J. and Moss-Racusin, C.A. (2009), "Engaging Men in Gender Initiatives: What Change Agents Need to Know", available at: http://www.catalyst.org/publication/323/engaging-men-in-gender-initiativeswhat-change-agents-need-to-know.

Reyna, C., Tucker, A., Korfmacher, W. and Henry, P.J. (2005), "Searching for Common Ground between Supporters and Opponents of Affirmative Action", Political Psychology, Vol. 26 No. 5, pp. 667-682. 
Rosener, J.B. (1990), “Ways Women Lead”, Harvard Business Review, Vol. 68 No. 6, pp. 119-125.

Rosin, H. (2012), The End of Men and the Rise of Women, Penguin, London.

Sawyer, K. and Valerio, A.M. (2018), "Making the case for male champions for gender inclusiveness at work", Organizational Dynamics, Pergamon, Vol. 47 No. 1, pp. 1-7.

Schein, E.H. (2010), Organizational Culture and Leadership, Jossey Bass, San Francisco.

Schein, V.E. (1973), “The Relationship between sex role stereotypes and requisite management characteristics", Journal of Applied Psychology, Vol. 57, pp. 95100.

Sczesny, S., Bosak, J., Neff, D. and Schyns, B. (2004), "Gender stereotypes and the attribution of leadership traits: A cross-cultural comparison", Sex Roles, Vol. 51 No. 11/12, pp. 631-645.

Seierstad, C. and Opsahl, T. (2011), "For the few not the many? The effects of affirmative action on presence, prominence, and social capital of female directors in Norway", Scandinavian Journal of Management, Vol. 27 No. 1, pp. $44-54$.

Simpson, R., Ross-Smith, A. and Lewis, P. (2010), "Merit, special contribution and choice: How women negotiate between sameness and difference in their organizational lives", Gender in Management: An International Journal, Vol. 25 No. 3, pp. 198-207.

Sliwa, M. and Johansson, M. (2013), "The discourse of meritocracy contested/reproduced: Foreign women academics in UK business schools", Organization, Vol. 21 No. 6, pp. 821-843.

Speer, S.A. and Potter, J. (2000), “The management of heterosexist talk: conversational resources and prejudiced claims", Discourse \& Society, Vol. 11 No. 4, pp. 543-572.

Stead, V. (2013), "Learning to deploy (in)visibility: An examination of women leaders’ lived experiences”, Management Learning, Vol. 44 No. 1, pp. 63-79. Teigen, M. (2012), "Gender Quotas on Corporate Boards: On the Diffussion of a Distinct National Poilicy Reform”, in Teigen, M. and Engelstad, F. (Eds.), Firms, Boards and Gender Quotas: Comparative Perspectives, Comparative Social Research, Vol. 29, Emerald, Bradford, pp. 115-146. 
Tienari, J., Quack, S. and Theobald, H. (2002), “Organizational Reforms, ‘Ideal Workers' and Gender Orders: A Cross-Societal Comparison", Organization Studies, Sage PublicationsSage CA: Thousand Oaks, CA, Vol. 23 No. 2, pp. 249-279.

de Vries, J.A. (2015), “Champions of gender equality: Female and male executives as leaders of gender change", Equality, Diversity and Inclusion: An International Journal, Vol. 34 No. 1, pp. 21-36.

Wahl, A. (2014), "Male Managers Challenging and Reinforcing the Male Norm in Management", NORA - Nordic Journal of Feminist and Gender Research, Vol. 22 No. 2, pp. 131-146.

Wajcman, J. (1996), “Desperately Seeking Differences: Is Management Style Gendered?", British Journal of Industrial Relations, Vol. 34 No. 3, pp. 333-349. Wang, M. and Kelan, E. (2013), “The Gender Quota and Female Leadership: Effects of the Norwegian Gender Quota on Board Chairs and CEOs", Journal of Business Ethics, Vol. 117 No. 3, pp. 449-466.

Webb, J. (1997), “The Politics of Equal Opportunity”, Gender, Work and Organization, Vol. 4 No. 3, pp. 159-169.

West, C. and Zimmerman, D.H. (1987), “Doing Gender”, Gender \& Society, Vol. 1 No. 2, pp. 125-151.

Wetherell, M. and Potter, J. (1988), "Discourse analysis and the identification of interpretative repertoires", in Antaki, C. (Ed.), Analysing Everyday Explanation A Case Book of Methods, Sage, London, pp. 168-183.

\footnotetext{
${ }^{\mathrm{i}}$ The transcription system is an adapted and simplified version of the Jefferson system (.) is a short notable pause, (0.9) an exactly timed longer pause (more than 5 seconds, here 9 seconds), (inaud) inaudible, (text) transcriber clarification on unclear parts of tape, ((text)) annotation of non-verbal activity or supplemental information, (...) material deliberately omitted, '...' direct speech reported by interviewee, wor- sharp cut off, abrupt halt or interruption of utterance, wo:rd extreme stretching of preceding sound, prolongation of a sound, HAHA loud laughter, HEHE laughter, TEXT strong emphasis or loud volume of speech, ${ }^{\wedge} \mathrm{Text} \mathrm{t}^{\wedge}$ quieter than usual, [...] start and end point of overlapping talk, = break and subsequent continuation of a single utterance, $<$ text $>$ indicates that the speech was delivered much slower than usual for the speaker, $>$ text $<$ indicates that the speech was delivered much faster than usual for the speaker, (hhh) audible exhalation, (.hhh) audible inhalation.
} 